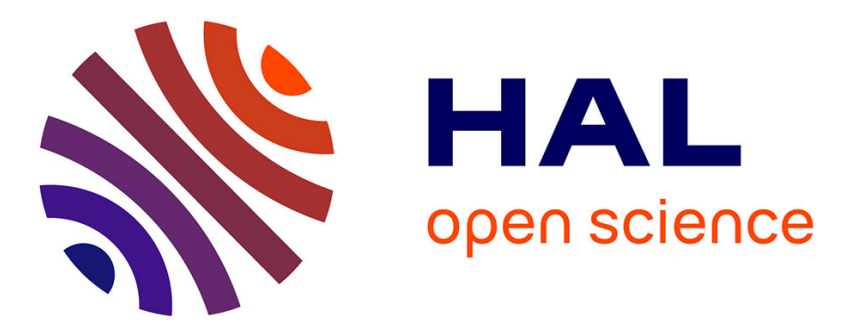

\title{
Nylon-Oligomer Hydrolase Promoting Cleavage Reactions in Unnatural Amide Compounds
}

\author{
Katsumasa Kamiya, Takeshi Baba, Mauro Boero, Toru Matsui, Seiji Negoro, \\ Yasuteru Shigeta
}

\section{- To cite this version:}

Katsumasa Kamiya, Takeshi Baba, Mauro Boero, Toru Matsui, Seiji Negoro, et al.. Nylon-Oligomer Hydrolase Promoting Cleavage Reactions in Unnatural Amide Compounds. Journal of Physical Chemistry Letters, 2014, 5 (7), pp.1210-1216. 10.1021/jz500323y • hal-02991778

\section{HAL Id: hal-02991778 \\ https://hal.science/hal-02991778}

Submitted on 4 Dec 2020

HAL is a multi-disciplinary open access archive for the deposit and dissemination of scientific research documents, whether they are published or not. The documents may come from teaching and research institutions in France or abroad, or from public or private research centers.
L'archive ouverte pluridisciplinaire HAL, est destinée au dépôt et à la diffusion de documents scientifiques de niveau recherche, publiés ou non, émanant des établissements d'enseignement et de recherche français ou étrangers, des laboratoires publics ou privés. 


\title{
A Nylon-oligomer Hydrolase Promoting Cleavage Reactions in Unnatural Amide Compounds
}

\author{
Katsumasa Kamiya, ${ }^{* \dagger}$ Takeshi Baba, ${ }^{\dagger}$ Mauro Boero, ${ }^{\S}$ Toru Matsui, " Seiji Negoro, ${ }^{\perp}$ \\ and Yasuteru Shigeta
}

${ }^{\dagger}$ Center for Basic Education and Integrated Learning, Kanagawa Institute of Technology, 1030 Shimo-Ogino, Atsugi, Kanagawa, 243-0292, Japan

ॠraduate School of Engineering Science, Osaka University, Toyonaka, Osaka 560-8531, Japan

${ }^{\S}$ Institut de Physique et Chimie des Matériaux de Strasbourg, UMR 7504 CNRS and University of Strasbourg, 23 rue du Loess, 67034 Strasbourg, France

"Advanced Institute for Computational Science, RIKEN, Chuo-ku, Kobe, Hyogo 650-0047, Japan

${ }^{\perp}$ Graduate School of Engineering, University of Hyogo, Himeji, Hyogo 671-2280, Japan

${ }^{\#}$ CREST, Japan Science and Technology Agency (JST), Kawaguchi, Saitama 332-0012 Japan

\section{Corresponding Author}

*katsumasa.kamiya@gen.kanagawa-it.ac.jp 
The active site of 6-aminohexanoate-dimer hydrolase, a nylon-6 byproduct-degrading enzyme with a $\beta$-lactamase fold, possesses a Ser112/Lys115/Tyr215 catalytic triad similar to the one of penicillin-recognizing family of serine-reactive hydrolases, but includes a unique Tyr170 residue. By using a reactive quantum mechanics / molecular mechanics (QM/MM) approach, we work out its catalytic mechanism and related functional/structural specificities. At variance with other peptidases, we show that the involvement of Tyr170 in the enzyme-substrate interactions is responsible for a structural variation in the substrate-binding state. The acylation via a tetrahedral intermediate is the rate-limiting step, with a free-energy barrier of $\sim 21 \mathrm{kcal} / \mathrm{mol}$, driven by the catalytic triad Ser112, Lys115, and Tyr215, acting as a nucleophile, general base, and general acid, respectively. The functional interaction of Tyr170 with this triad leads to an efficient disruption of the tetrahedral intermediate, promoting a conformational change of the substrate favorable for proton donation from the general acid.

\section{TOC GRAPHICS}

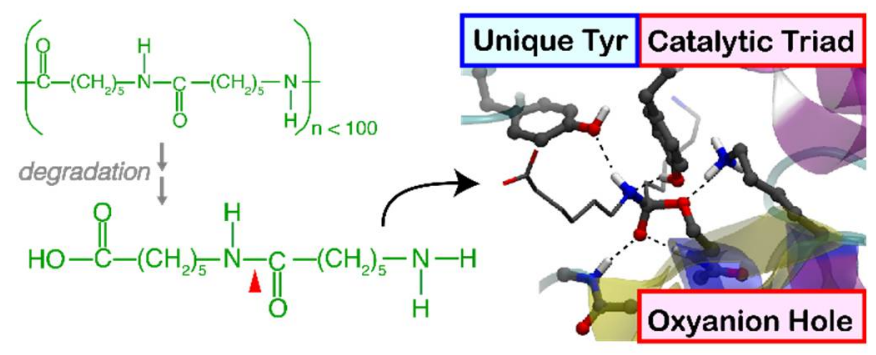

\section{KEYWORDS}

Enzymes $\bullet$ Hydrolases $\bullet$ Catalytic triad $\bullet$ Nylon-oligomer $\bullet$ Peptidase 
Amide bond cleavage is a fundamental reaction of living organisms, ${ }^{1-9}$ and an important case is represented by peptidases catalyzing the hydrolysis of peptide bonds. ${ }^{1-8}$ Such an enzyme is ubiquitous and exhibits either nonspecific protein degradation or highly specific cleavage of protein substrates in physiological processes, such as activation of zymogens and hormone release. ${ }^{1,2,5-8}$ From the evolutionary standpoint, proteases with purely digestive functions have developed a high degree of specificity and efficiency to degrade amide compounds, in virtue of a characteristic set of functional amino acid residues in the active site organized in a specific configuration. ${ }^{1,7}$ The most common amide bond cleavage mechanism of peptidases is the polarization of a peptide bond upon nucleophilic attack on the carbon-oxygen bond, assisted by a proton abstraction from the nucleophile and following a proton donation to the peptide nitrogen in a general base/acid (Scheme 1). ${ }^{1-8}$

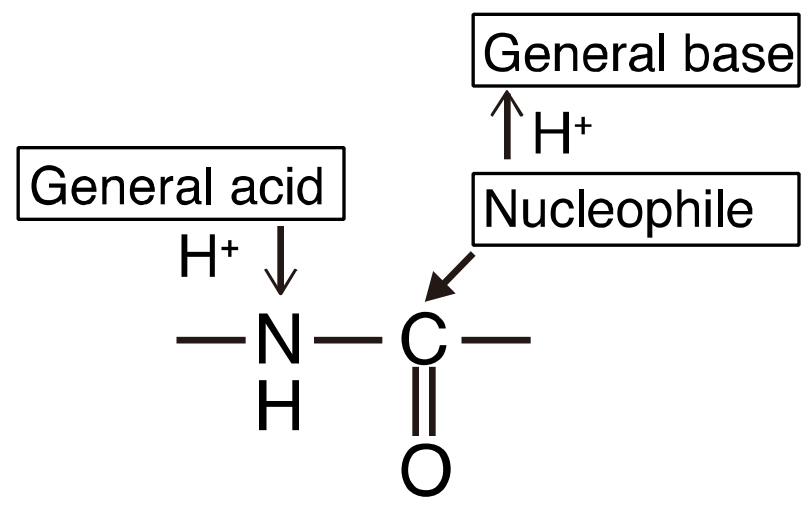

Scheme 1. Common mechanism of amide bond cleavage by peptidases.

Besides natural compounds, a peptidase exists having the ability to cleave the amide bond in artificial compounds. Such a hydrolase promotes the degradation of a nylon-6 manufacture 
byproduct, namely 6-aminohexanoate (Ahx) oligomers (termed nylon-oligomers). ${ }^{10-19}$ Nylonoligomer hydrolases were discovered in a bacterium (Arthrobacter sp. KI72) from soil near nylon factories in $1972 .{ }^{10}$ The bacterium evolved under environmental conditions developing a specific ability to use nylon-oligomers as a source of $\mathrm{C}$ and $\mathrm{N}$, exploiting three types of nylonoligomer hydrolases: Ahx-cyclic-dimer hydrolase (NylA), Ahx-linear-dimer (Ald) hydrolase (NylB), and endotype Ahx-oligomer hydrolase (NylC). ${ }^{11}$ Among the identified nylon-oligomer hydrolases, NylB has recently been the target of extensive investigations. ${ }^{13-19}$ The NylB enzyme has been shown to possess not only a degrading activity of amide compounds, e.g. $\mathrm{NH}_{2}-$ $\left(\mathrm{CH}_{2}\right)_{5}-\mathrm{CO}-\mathrm{NH}-\left(\mathrm{CH}_{2}\right)_{5}-\mathrm{COOH}+\mathrm{H}_{2} \mathrm{O} \rightarrow 2 \mathrm{NH}_{2}-\left(\mathrm{CH}_{2}\right)_{5}-\mathrm{COOH}$, but also an esterase activity on various carboxyl esters with different acyl chains, similar to other peptidases (e.g. serine proteases) ${ }^{13,14} \mathrm{X}$-ray structures of NylB revealed similarities with several enzymes of the penicillin-recognizing family of serine-reactive hydrolases, specifically, D-alanyl-D-alanine (DD) carboxypeptidase (DD-peptidase) from Streptomyces sp. R61, carboxylesterase (EstB) from Burkholderia gladioli, and Class C $\beta$-lactamase. ${ }^{15-19}$ The crystal structure also evidenced that the binding site of an Ald substrate includes a catalytic triad Ser112/Lys115/Tyr215 and an oxyanion hole region (Figure 1a), located at positions close to those of the penicillin-recognizing enzymes.

However, in the NylB active site, a tyrosine residue Tyr170 exists, having no analog in any member of the penicillin-recognizing family for the serine-reactive hydrolases. ${ }^{16}$ The NylB substrate-binding X-ray structure showed that Tyr170 forms a hydrogen-bond (H-bond) with the Ald substrate near the Ser112/Lys115/Tyr215 catalytic triad (Figure 1a). 
(a)

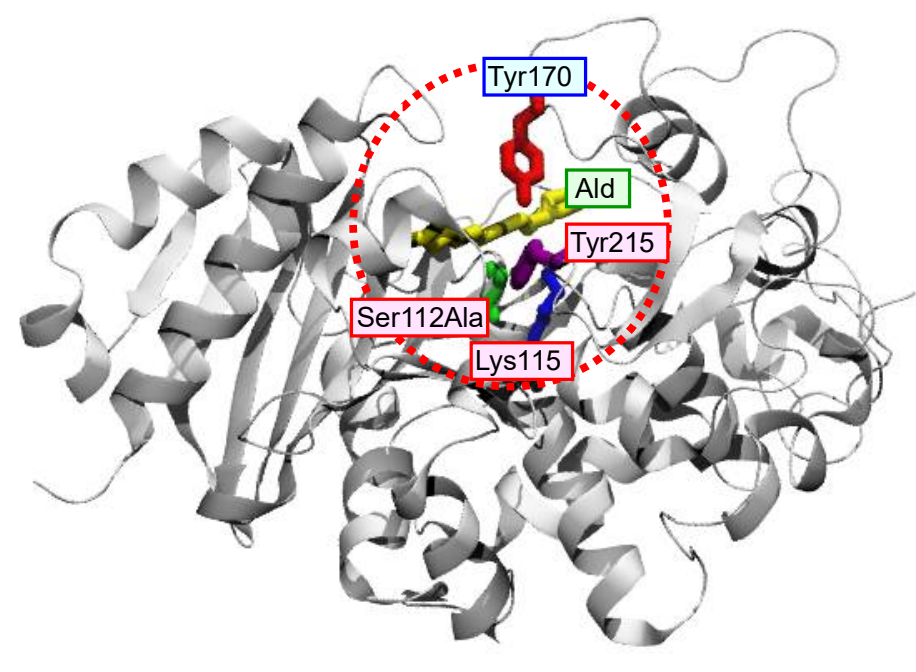

(b)

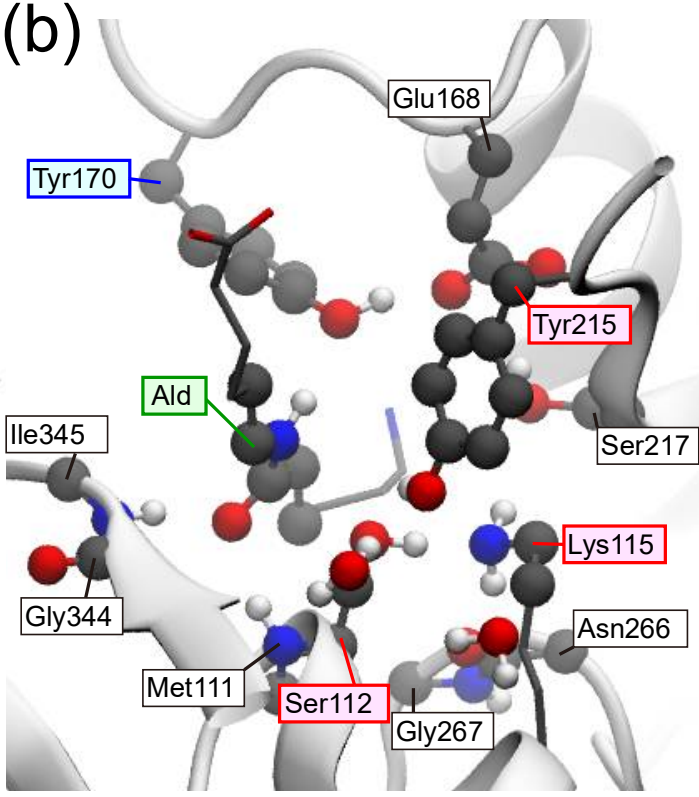

Figure 1. (a) X-ray structure of the NylB-type nylon-oligomer hydrolase. The Ser112/Lys115/Tyr215 catalytic triad and the unique Tyr170 residue are shown in green, blue, purple, and red, respectively, while the Ald substrate is yellow. (b) Atomic-level detail of the active site for the QM/MM model, corresponding to the portion inside the red dotted circle of panel (a). The QM atoms are shown as balls and the MM subsystem as ribbon model. Solvent water molecules are not shown for clarity. Here and in the following figures, the color code for the atoms is gray for $\mathrm{C}$, red for $\mathrm{O}$, blue for $\mathrm{N}$, and white for $\mathrm{H}$.

Concerning its functional role, a site-directed mutagenesis of Tyr170 to a phenylalanine exhibited a decrease of Ald degradation activity to $1.4 \%$ with respect to the wild type, indicating that Tyr170 is directly involved in the degradation process. ${ }^{17}$ Moreover, a comparison between substrate-binding/-unbound NylB crystal structures evidenced an induced-fit motion of Tyr170. ${ }^{17}$ This indicates that Tyr170 enhances Ald binding, a conclusion supported also by our former 
simulations. ${ }^{20}$ However, no clear understanding of the Tyr170 catalytic role and of the structurefunction relationships of the catalytic triad has been obtained to date. To shed light on these issues, we studied the catalytic mechanisms of Ald degradation by NylB-type nylon-oligomer hydrolase using hybrid QM/MM dynamics in combination with free energy sampling ${ }^{21-34}$ for the activated processes. The equilibrium structure of the active site of the wild-type (WT) NylB in a substrate-binding state was determined via QM/MM unbiased dynamics. Results are reported in Table 1 as averages over $\sim 8$ ps at $300 \mathrm{~K}$. For comparison, the corresponding parameters of the NylB X-ray structures ${ }^{18}$ and structurally similar enzymes of the penicillin-recognizing family of the serine-reactive hydrolases ${ }^{35-39}$ are included. The calculated distances for the WT NylB with the Ald substrate show a rather good agreement with the available NylB crystal structures, providing support to our approach. One exception is the distance of Lys115- $\mathrm{N}_{\zeta}$ and Tyr215-O Such a discrepancy might be due to S112A mutation effects on the Ald-binding X-ray structure to inactivate the enzyme (details in the Supporting Information).

A comparison with other penicillin-recognizing enzymes shows that the H-bond pattern in the catalytic triad and oxyanion hole of the substrate-binding NylB is basically similar to those enzymes (Table 1). In the NylB catalytic triad, the nucleophile Ser112- $\mathrm{O}_{\gamma}$ forms H-bonds with both Lys115- $\mathrm{N}_{\zeta}$ and Tyr215- $\mathrm{O}_{\eta}$. The distance between the side chains of Lys115 and Tyr215 (about $3.7 \AA$ ) is slightly above the typical H-bond ${ }^{40}$, and the estimation of $\mathrm{H}$ nuclear magnetic resonance (NMR) chemical shift indicates that no H-bonds exists between these residues (see the Supporting Information). The backbone N atoms of Ser112 and Ile345 also form H-bonds with the amide oxygen of the Ald substrate. At variance with the common features discussed so far, 
NylB exhibits a structural diversity in the substrate binding. In our simulated NylB, the Ald amide binds to Tyr170- $\mathrm{O}_{\eta}$ via a $\mathrm{H}-$ bond (Table 1).

Table 1. Main geometrical parameters for the active site of NylB, R61 DD-peptidase, EstB carboxylesterase, and Class $\mathrm{C} \beta$-lactamase; the corresponding amino acid residues constituting the catalytic triad and oxyanion hole region in the latter three enzymes are given in Table S1.

\begin{tabular}{|c|c|c|c|c|c|c|c|c|c|}
\hline$\AA /$ degrees & $\begin{array}{l}\text { NylB } \\
\\
\text { QM/MM } \\
\text { Substrate- } \\
\text { binding } \\
\text { (WT) }\end{array}$ & $\begin{array}{l}\text { NylB } \\
\text { X-ray } \\
\text { Substrate- } \\
\text { binding } \\
\left(\mathrm{S} 112 \mathrm{~A}^{a}\right)\end{array}$ & $\begin{array}{l}\text { NylB } \\
\text { X-ray } \\
\text { Substrate- } \\
\text { unbound } \\
\left(\mathrm{WT}^{b}\right)\end{array}$ & $\begin{array}{l}\text { R61 DD- } \\
\text { peptidase } \\
\text { X-ray } \\
\text { Substrate- } \\
\text { binding } \\
\text { (WT cross- } \\
\text { linking }{ }^{c} \text { ) }\end{array}$ & $\begin{array}{l}\text { R61 DD- } \\
\text { peptidase } \\
\text { X-ray } \\
\text { Substrate- } \\
\text { unbound } \\
\left(\mathrm{WT}^{d}\right)\end{array}$ & $\begin{array}{l}\begin{array}{l}\text { EstB } \\
\text { carboxyl- } \\
\text { esterase }\end{array} \\
\text { X-ray } \\
\text { Substrate- } \\
\text { binding } \\
\text { (WT } \\
\text { tetrahedral } \\
\text { intermediate } \\
\text { analoge }\end{array}$ & $\begin{array}{l}\text { EstB } \\
\text { carboxyl- } \\
\text { esterase } \\
\text { X-ray } \\
\text { Substrate- } \\
\text { unbound } \\
\left(\mathrm{WT}^{\prime}\right)\end{array}$ & $\begin{array}{l}\text { Class C } \beta \text { - } \\
\text { lactamase } \\
\text { X-ray } \\
\text { Substrate- } \\
\text { binding } \\
\left(\mathrm{S}_{64 G^{g}}\right)\end{array}$ & $\begin{array}{l}\text { Class C } \beta \text { - } \\
\text { lactamase } \\
\text { X-ray } \\
\text { Substrate- } \\
\text { unbound } \\
\left(\mathrm{WT}^{h}\right)\end{array}$ \\
\hline $\begin{array}{l}\mathrm{S} 112-\mathrm{O}_{\gamma^{-}} \\
\mathrm{K} 115-\mathrm{N}_{\zeta} \\
{[\AA]}\end{array}$ & $2.72 \pm 0.11$ & none & 2.60 & 4.08 & $4.13 / 5.30$ & 3.18 & 2.98 & none & 2.82 \\
\hline $\begin{array}{l}\mathrm{S} 112-\mathrm{O}_{\gamma^{-}} \\
\mathrm{Y} 215-\mathrm{O}_{\eta} \\
{[\AA]}\end{array}$ & $2.88 \pm 0.17$ & none & 2.90 & 3.17 & $3.76 / 3.68$ & 2.96 & 2.53 & none & 2.93 \\
\hline $\begin{array}{l}\mathrm{K} 115-\mathrm{N}_{\zeta}- \\
\mathrm{Y} 215-\mathrm{O}_{\eta} \\
{[\AA]}\end{array}$ & $3.74 \pm 0.23$ & 2.60 & 3.71 & 3.27 & $2.76 / 3.21$ & 2.73 & 2.69 & 2.91 & 3.33 \\
\hline $\begin{array}{l}\text { Y170-O }{ }_{\eta}- \\
\text { Ald-N } \\
{[\AA]}\end{array}$ & $3.16 \pm 0.19$ & $3.08 / 3.04$ & none & none & none & none & none & none & none \\
\hline $\begin{array}{l}\text { S112-N- } \\
\text { Ald-O } \\
{[\AA]}\end{array}$ & $3.23 \pm 0.21$ & $2.96 / 3.03$ & none & 2.72 & none & 2.92 & none & 2.80 & none \\
\hline $\begin{array}{l}\text { I345-N- } \\
\text { Ald-O } \\
{[\AA]}\end{array}$ & $2.97 \pm 0.14$ & $2.81 / 2.86$ & none & 2.79 & none & 2.66 & none & 2.86 & none \\
\hline $\begin{array}{l}\text { S112-O } \gamma_{\gamma^{-}} \\
\text {Ald-C } \\
{[\AA]}\end{array}$ & $3.01 \pm 0.16$ & none & none & 2.91 & none & 1.64 & none & none & none \\
\hline $\begin{array}{l}\text { Ald-N- } \\
\text { Ald-C } \\
{[\AA]}\end{array}$ & $1.35 \pm 0.02$ & 1.33 & none & 1.40 & none & none & none & none & none \\
\hline $\begin{array}{l}\mathrm{S}_{112-\mathrm{O}_{\gamma}-} \\
\text { Ald-C- } \\
\text { Ald-O }\end{array}$ & $87.23 \pm 5.42$ & none & none & 93.10 & none & 109.34 & none & none & none \\
\hline
\end{tabular}


\begin{tabular}{|l|l|l|l|l|l|l|l|}
\hline [degrees] & & & & & & & \\
\hline
\end{tabular}

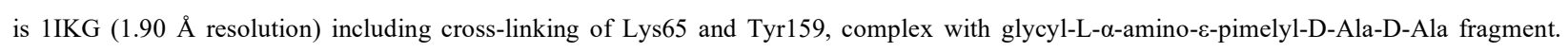
${ }^{d} \mathrm{PDB}$ entry is $3 \mathrm{PTE}\left(1.60 \AA\right.$ A resolution) including two conformations for Lys65 and Tyr159. ${ }^{e} \mathrm{PDB}$ entry is $1 \mathrm{CI} 9$ (1.80 $\AA$ resolution), the complex

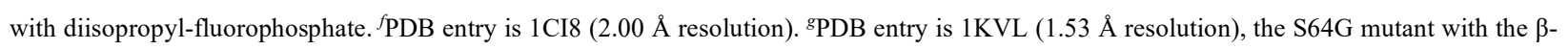
lactam cephalothin. ${ }^{h} \mathrm{PDB}$ entry is $1 \mathrm{KE} 4$ (1.72 Å resolution).

This hydrogen bonding leads to two structural differences around the substrate amide group between NylB and the other penicillin-recognizing enzymes. The first one stems from the absence of any H-bond of the amide of the Ald substrate with side chains of the NylB catalytic triad (Table 1). Conversely, the substrate-binding X-ray structures of the DD-peptidase and the Class C $\beta$-lactamase showed a clear binding of the substrate to the side chains of their catalytic triads. ${ }^{35,37}$ The second one stems from the distances of the carbonyl $\mathrm{O}$ of the substrate from the oxyanion hole region: These distances in the WT NylB are longer by $4-19 \%$ than those in the other penicillin-recognizing enzymes (Table 1), and the net effect is that the position of the Ald amide group toward the nucleophile is slightly altered in the NylB active site. As shown in Table 1, the distance Ser112- $\mathrm{O}_{\gamma}-$ Ald-C and angle Ser112- $\mathrm{O}_{\gamma}-\mathrm{Ald}-\mathrm{C}-\mathrm{Ald}-\mathrm{O}$ are $3 \AA$ and $87^{\circ}$, respectively, whereas in the DD-peptidase case the corresponding geometrical parameters are 2.9 $\AA$ and $93^{\circ}$. Although all these values are close to the energetically preferred distance and angle reported in Ref. $41\left(\sim 3 \AA\right.$ and $\left.\sim 100-110^{\circ}\right)$, the difference between NylB and the DD-peptidase indicates that the involvement of Tyr170 in the enzyme-substrate interactions in NylB leads to an alternative stable state for the substrate binding in the amide bond cleavage.

To get a deeper insight into the Ald amide bond cleavage by NylB and the functional interactions between the catalytic triad and Tyr170, we investigated the cleavage reaction of the Ald amide bond in acylation via QM/MM dynamical simulations coupled to metadynamics ${ }^{28-30}$. As reaction 
coordinates (RCs), two distances were selected: (1) the distance between Ser112- $\mathrm{O}_{\gamma}$ and the Ald carboxyl carbon, and (2) the distance between the Ald amide nitrogen and carboxyl carbon. The results are summarized in Figures 2 and 3 in terms of the free-energy surface (FES) as a function of the two RCs and key configurations characterizing the cleavage reaction.

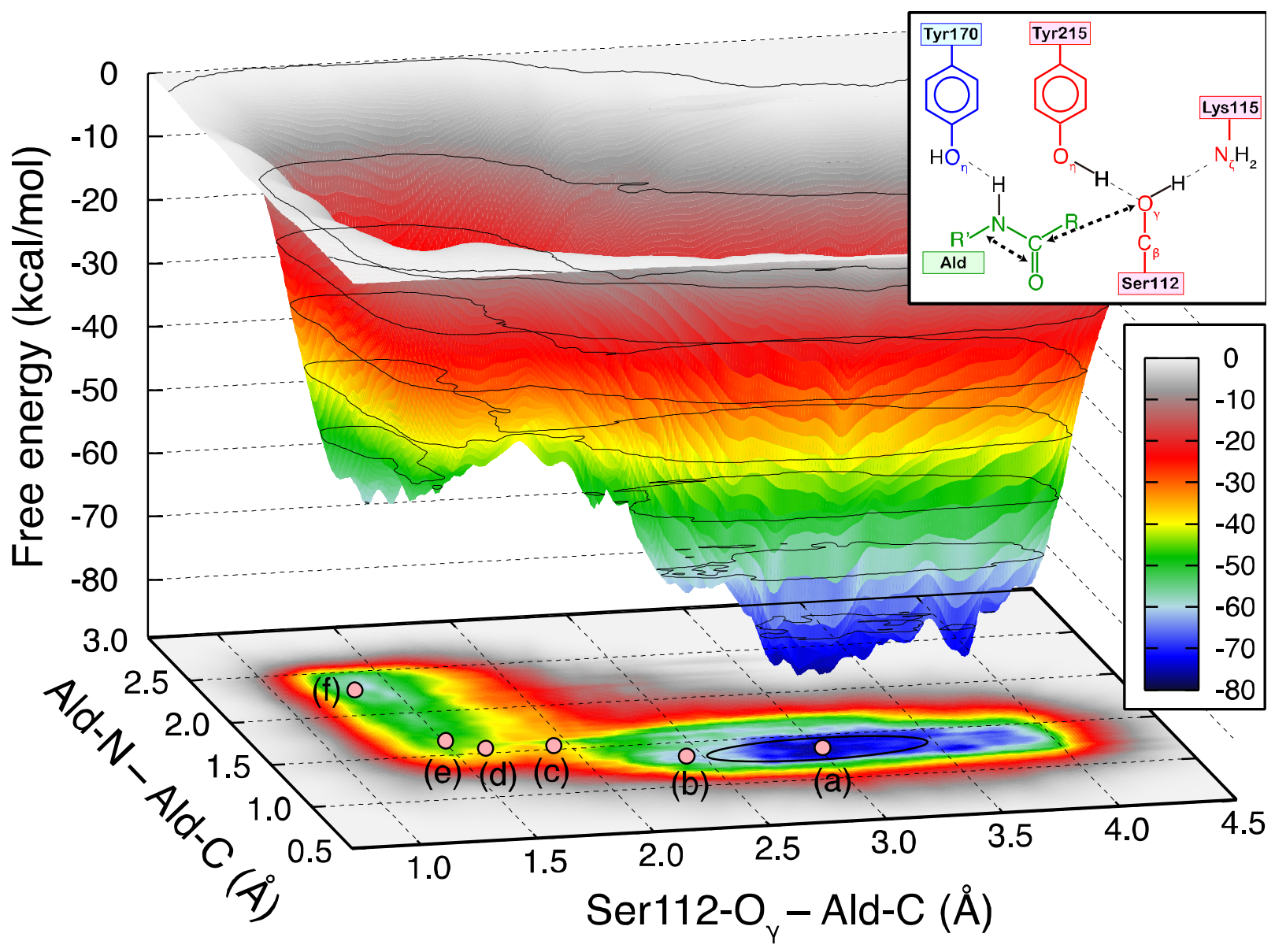

Figure 2. Free-energy surface as a function of the Ser112- $\mathrm{O}_{\gamma}-\mathrm{Ald}-\mathrm{C}$ and the Ald-N-Ald-C distances. The circle in the contour map shows the area to which the system is thermally accessible by standard unbiased dynamics. 
(a)

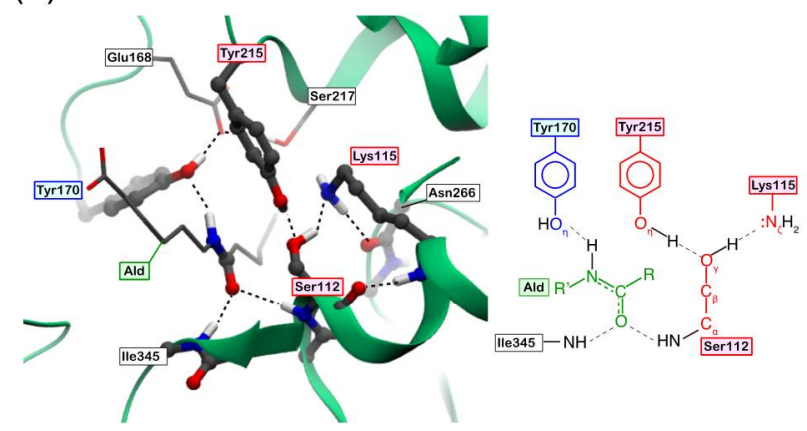

(c)

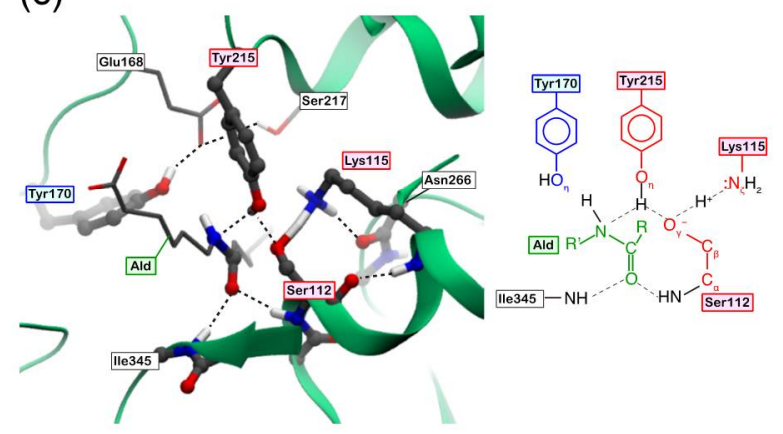

(e)

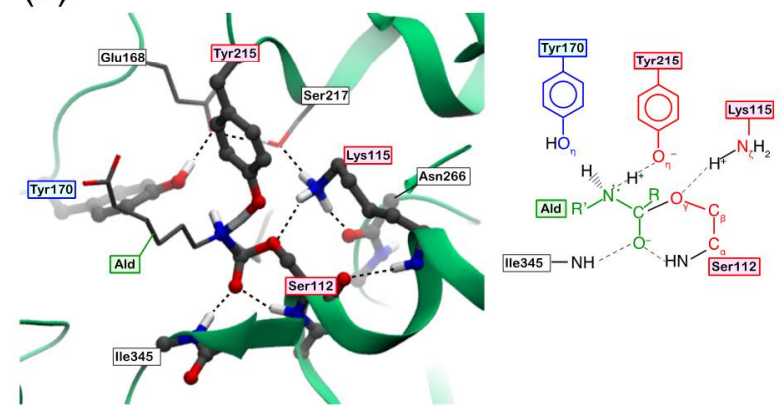

(b)

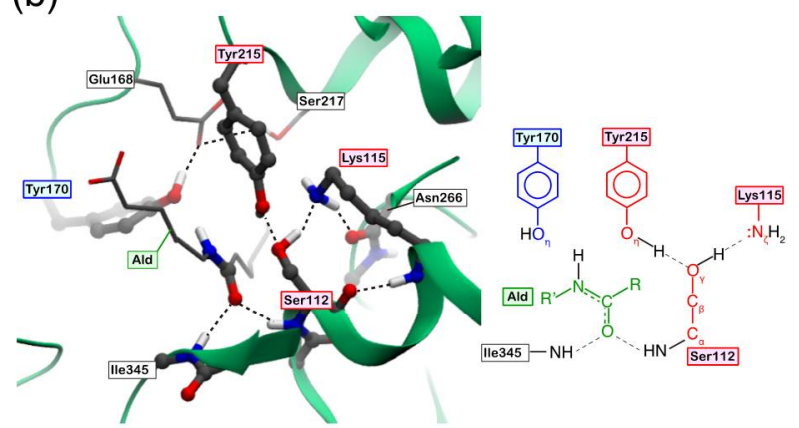

(d)

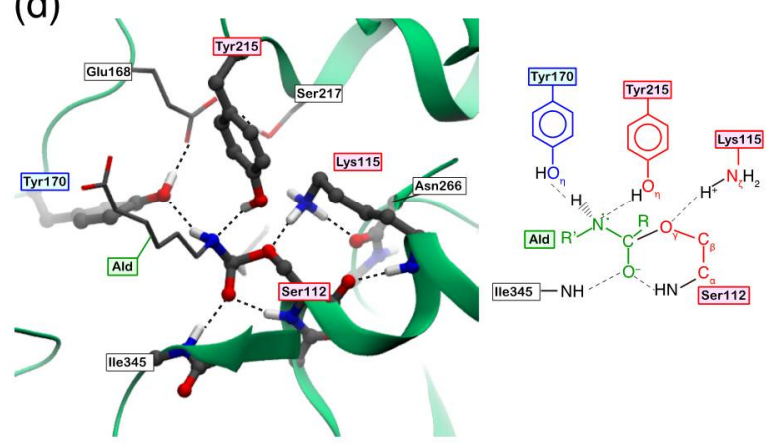

(f)

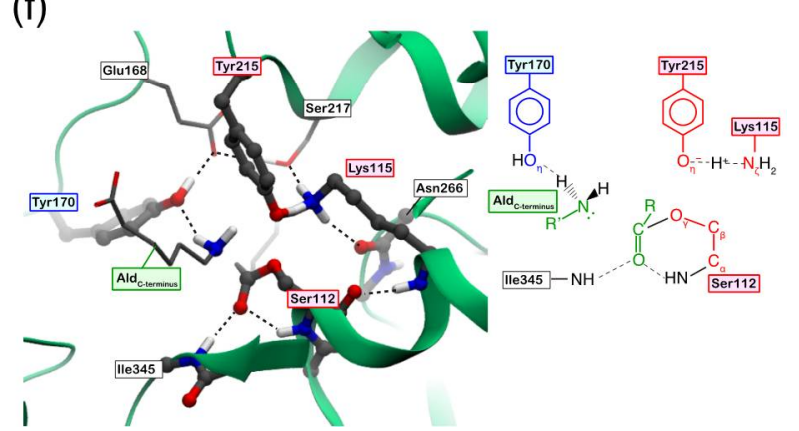

Figure 3. Snapshots of the structures of the various intermediate states realized by the system during the acylation. The labels (a)-(f) refer to the points marked by dots in Figure 2. The most relevant atoms are drawn as balls and sticks, and H-bonds are indicated by dashed lines.

The cleavage mechanism of the Ald amide bond in acylation of NylB is as a two-step reaction from the viewpoint of FES. The first step occurs along the reaction path joining the initial local minimum (a) to the adjacent local minimum (b) of the FES (Figure 2). The initial minimum is located in a deep basin, where the enzyme-substrate complex is in thermal equilibrium and 
fluctuates inside the area enclosed by a circle in Figure 2. The corresponding representative structure around the active site is sketched in Figure 3a. The FES local minimum (a) corresponds to a remarkable stabilization of the Ald substrate binding, induced by the unique H-bond interactions of the Ald amide group with Tyr170 and the oxyanion hole region in NylB. On the other hand, the subsequent local minimum (b) is positioned in a shallow basin, energetically located at $\sim 14 \mathrm{kcal} / \mathrm{mol}$ above (a). As shown in Figure 3b, the corresponding structure shows that Tyr170 is detached from the Ald substrate, and the amide group slides into a pocket formed by the oxyanion hole.

The second reaction step is the cleavage of the amide bond and the formation of the acyl-enzyme, along the reaction path from (b) to (f) in Figure 2. This is the rate-limiting step and is characterized by a free-energy barrier, from (b) to (c), of $\sim 21 \mathrm{kcal} / \mathrm{mol}$, in quite good agreement with the reported experimental value of $\sim 17 \mathrm{kcal} / \mathrm{mol}$ estimated from the transition state theory assuming the experimental $k_{\text {cat }}$ value of $3.2 \mathrm{~s}^{-1}$ for WT NylB. ${ }^{18}$ This value is also in the range of activation barriers for the acylation step in serine-reactive hydrolases $(18-26 \mathrm{kcal} / \mathrm{mol}) .{ }^{42-47}$ Hence, we can infer that the reaction-ready state of NylB is likely to correspond to the substratebinding state of other serine-reactive hydrolases.

The resulting reaction mechanism is mainly the one typical of a catalytic triad, but it involves the crucial participation of Tyr170 (Figure 3, form (c) to (f)). A proton abstraction from the nucleophile of Ser112- $\mathrm{O}_{\gamma} \mathrm{H}$ is triggered by Lys115 (Figure 3 (c)). Simultaneously, the nucleophilic attack of Ser112- $\mathrm{O}_{\gamma}{ }^{-}$on the amide carbon occurs, leading to the formation of a tetrahedral intermediate (Figure $3(\mathrm{~d})$ ). This intermediate is then stabilized by the oxyanion hole 
consisting of Ser112 and Ile345 backbone NHs, as well as Lys115- $\mathrm{N}_{\zeta} \mathrm{H}_{3}{ }^{+}$, as in the conventional mechanism of the serine-reactive hydrolases. ${ }^{1-9}$

However, the functional interaction of Tyr170 with the catalytic triad leads to a remarkable stereoelectronic effect on the tetrahedral intermediate. As shown in Figure 3 (d), the formation of a Ser112- $\mathrm{O}_{\gamma}-$ Ald $\mathrm{C}$ single bond after the nucleophilic attack leads to a conversion of the $\mathrm{N}-\mathrm{C}$ partial double bond in the amide into a single bond. In contrast, Tyr170 works as an H-bond acceptor for the Ald amide $\mathrm{N}$ forming another H-bond with the adjacent Glu168 residue. Simultaneously, Tyr215 of the catalytic triad acts as an H-bond donor for the Ald amide. As a result of these three interactions, the $\mathrm{NH}$ moiety in the amide group takes an anti-periplanar configuration with respect to the Ser112- $\mathrm{O}_{\gamma}-\mathrm{Ald} \mathrm{C}$ bond, thus assuming a stereochemically favorable conformation to accept the proton from $\mathrm{Tyr} 215-\mathrm{O}_{\eta} \mathrm{H}$ without requiring large positional changes. In addition to this stereochemical effect of Tyr170 on the tetrahedral intermediate, electrostatic interactions of Tyr215- $\mathrm{O}_{\eta} \mathrm{H}$ with a positively charged Lys $115-\mathrm{N}_{\zeta} \mathrm{H}_{3}{ }^{+}$, located between $\mathrm{O}_{\eta}$ and $\mathrm{N}_{\zeta}$ at at distances of $\sim 3.5 \AA$, contribute in a concerted way to the proton transfer from Tyr215-O $\mathrm{O}_{\eta}$ to the amide $\mathrm{N}$. This, in turn, leads to the cleavage of the Ald amide bond and the formation of the acyl-enzyme (Figure 3 (e) and (f)). Although the reaction path was sampled until the departing amine (6-aminohexanoate, i.e. carboxyl residue in Ald) reached the border of the $\mathrm{QM}$ cell, it is noteworthy that this leaving amine is caught by Tyr170 via a H-bond, suggesting that the release of the amine is accompanied by a Tyr170 structural change. Furthermore, Tyr215- $\mathrm{O}_{\eta}{ }^{-}$forms a strong $\mathrm{H}$-bond with $\mathrm{Lys} 115-\mathrm{N}_{\zeta} \mathrm{H}_{3}{ }^{+}$in the acyl-enzyme, analogous to the X-ray structure of covalent acyl enzyme complex of the DD-peptidase. ${ }^{48}$ 
Concerning the functional role of Tyr170 in the catalytic-triad-driven NylB reaction, our calculations indicate that Tyr170 enhances the proton transfer from Tyr215 (general acid) to the Ald amide $\mathrm{N}$ in the tetrahedral intermediate. This is consistent with the results of site-directed mutagenesis, where a conversion of Tyr170 to a phenylalanine decreases the Ald degradation activity with respect to the WT. ${ }^{17}$ The importance of such functional role stems from the stereoelectronic requirements for an efficient breakdown of the tetrahedral intermediate, an important issue in other serine proteases. ${ }^{4,43,49-51}$ In both cases, NylB and serine protease, a nucleophile and a general acid in a catalytic triad are located on the same side of the scissile amide bond. When the nucleophile attacks the amide bond, the $\mathrm{NH}$ of the amide group rotates around the scissile bond axis to accept the $\mathrm{H}^{+}$from the acid, provided that the acid does not undergo large displacements. In the case of $\mathrm{NylB}$, this rotation proceeds according to the nucleophilic attack by functional interactions among the Tyr170 residue and the catalytic triad along three steps: (1) the distance between Tyr215- $\mathrm{O}_{\eta}$ and the Ald amide $\mathrm{N}$ decreases during the nucleophilic attack (Figure 3 (b) and (c)), (2) Tyr215 starts pointing its $\mathrm{O}_{\eta}-\mathrm{H}$ bond toward the amide $\mathrm{N}$ to form an H-bond (Figure 3 (c)), and (3) Tyr170 moves back toward the amide $\mathrm{N}$ forming an $\mathrm{H}$-bond by rotating the $\mathrm{NH}$ moiety around the scissile bond toward Tyr170 (Figure 3 (d)). This mechanism, driven by the concerted action of the Tyr170 residue and the NylB catalytic triad, could efficiently induce the disruption of the tetrahedral intermediate because it does not require large displacements of the involved amino acid residues. This represents a significant novelty in the structure-function relationships of NylB active site, where the formation of a pre-organized environment suited to realize conventional catalytic-triad driven mechanisms was already evidenced for other proteins. ${ }^{52,53}$ 
The importance of the Tyr170 functional role can also be rationalized by comparison with a Class C $\beta$-lactamase sharing a structural similarity with the Ald hydrolase in the penicillinrecognizing family of the serine-reactive hydrolases. In the Class $C \beta$-lactamase, the tyrosine residue corresponding to Tyr215 forms two H-bonds with two nearby lysine residues, considered as a general base/acid. ${ }^{54}$ Concerning its proton donation to the substrate amide, such positively charged lysine residues could increase the acidity of the tyrosine. Conversely, a cooperation of the positively charged lysine would be negligible in NylB, because only one Lys115 residue is present near Tyr215, and no direct H-bond to Tyr215 exists. In this situation, the acidity of Tyr215 does not increase significantly, thus hindering the proton transfer.

Summarizing, we studied, via reactive simulations, the acylation of the Ald degradation by the NylB-type nylon-oligomer hydrolase. The depicted reaction mechanism evidences two crucial functional roles of a unique residue, Tyr170: (1) a stabilization of the substrate-binding state, and (2) an enhancement in the proton-donation from a general acid to the substrate amide $\mathrm{N}$ in the tetrahedral intermediate. The free-energy barrier for the rate-limiting step of the acylation is $\sim 21$ $\mathrm{kcal} / \mathrm{mol}$, providing also a quantitative information to the inspected reaction. Moreover, this discloses environmentally friendly and industrially appealing ways of disposing nylon wastes.

\section{Computational Methods}

The structural model of the WT NylB was constructed from the substrate-binding X-ray structure of the S112A mutant (PDB ID: 2ZMA) after replacing S112A with serine. The protonation states of Lys115 and Tyr215 in the catalytic triad were set to be neutral, corresponding to a general base for the nucleophile of Ser112. The system was thermalized at $300 \mathrm{~K}$ by classical molecular 
dynamics with AMBER ff99 force field ${ }^{21}$. The equilibrated system was then used for hybrid $\mathrm{QM} / \mathrm{MM}$ simulations, where the QM driver was the density functional theory framework ${ }^{22,23}$ in the generalized gradient approximation on the exchange and correlation functional after Hamprecht, Cohen, Tozer, and Handy $(\mathrm{HCTH}) .{ }^{24}$ A Car-Parrinello molecular dynamics ${ }^{25,26}$ approach was used with a Hamiltonian QM/MM coupling scheme according to Ref. 27. The QM region includes the Ser112/Lys115/Tyr215 catalytic triad, Tyr170, and their surrounding residues (Figure 1 (b)). The reaction pathways were sampled by the metadynamics approach. ${ }^{28-34}$ Additional computational details are provided in the Supporting Information.

\section{AUTHOR INFORMATION}

\section{Corresponding Author}

*Email: katsumasa.kamiya@gen.kanagawa-it.ac.jp

\section{ACKNOWLEDGMENT}

We acknowledge fruitful discussions with Y. Takano and H. Nakamura at Osaka University, and with F. Pietrucci and W. Andreoni at Ecole Polytechnique Fédérale de Lausanne (EPFL). This work was performed under the CECAM Visitors Program, CECAM-EPFL, Switzerland, and under the Cooperative Research Program of Institute for Protein Research, Osaka University. This research was supported by a Grant-in-Aid for Young Scientists (A) (Grant No. 22685003), Young Scientists (B) (Grant No. 22740259), and Priority Area "Computics" (Grant No. 25104716) from the Japan Society for the Promotion of Science. Simulations were performed on HPC facilities at the Institute for Solid-State Physics - The University of Tokyo and at the Research Center for Computational Science - Okazaki Research Facilities of the National 
Institutes of Natural Sciences. M.B. acknowledges GENCI under allocation x2013096092 and HPC-UdS EQUIP@MESO.

Supporting Information Available: Further details about the computational set-up, the reaction coordinates, the scatterplot of sampled points in reaction coordination space, and free energy analyses. This material is available free of charge at http://pubs.acs.org.

\section{REFERENCES}

(1) Neurath, H. Evolution of Proteolytic Enzymes. Science 1984, 224, 350-357.

(2) Phillips, M. A.; Fletterick, R. J. Proteases. Curr. Opin. Struct. Biol. 1992, 2, 713-720.

(3) Dodson, G.; Wlodawer, A. Catalytic Triads and Their Relatives. Trends. Biochem. Sci. 1998, 23, 347-352.

(4) Hedstrom, L. Serine Protease Mechanism and Specificity. Chem. Rev. 2002, 102, 45014523.

(5) Polgár, L. The Catalytic Triad of Serine Peptidases. Cell. Mol. Life Sci. 2005, 62, 21612172.

(6) Page, M. J.; Cera, E. D. Serine Peptidases: Classification, Structure and Function. Cell. Mol. Life Sci. 2008, 65, 1220-1236.

(7) Page, M. J.; Cera, E. D. Evolution of Peptidase Diversity. J. Biol. Chem. 2008, 283, 30010-30014.

(8) Cera, E. D. Serine Proteases. IUBMB Life. 2009, 61, 510-515.

(9) Pratt, R. F. Substrate Specificity of Bacterial DD-Peptidases (Penicillin-Binding Proteins). Cell. Mol. Life Sci. 2008, 65, 2138-2155. 
Kinoshita, S.; Kageyama, S.; Iba, K.; Yamada, Y.; Okada, H. Utilization of Cyclic Dimer and Linear Oligomers of $\varepsilon$-Aminocaproic Acid by Achromobacter guttatus KI 72. Agr. Biol. Chem. 1975, 39, 1219-1223.

Okada, H.; Negoro, S.; Kimura, H.; Nakamura, S. Evolutionary Adaptation of Plasmid-Encoded Enzymes for Degrading Nylon Oligomers. Nature 1983, 306, 203-206.

$$
\text { Negoro, S. Biodegradation of Nylon Oligomers. Appl. Microbiol. Biotechnol. }
$$
2000, 54, 461-466.

Negoro, S.; Mitamura, T.; Oka, K.; Kanagawa, K.; Okada, H. Determination of the Active-Site Serine of 6-Aminohexanoate-Dimer Hydrolase. Eur. J. Biochem. 1989, $185,521-524$.

Ohki, T.; Wakitani, Y.; Takeo, M.; Yasuhira, K.; Shibata, N.; Higuchi, Y.; Negoro, S. Mutational Analysis of 6-Aminohexanoate-Dimer Hydrolase: Relationship between Nylon Oligomer Hydrolytic and Esterolytic Activities. FEBS Lett. 2006, 580, 5054-5058.

Ohki, T.; Mizuno, N.; Shibata, N.; Takeo, M.; Negoro, S.; Higuchi, Y. Crystallization and X-ray Diffraction Analysis of 6-Aminohexanoate-Dimer Hydrolase from Arthrobacter sp. KI72. Acta. Cryst. 2005, F61, 928-930.

Negoro, S.; Ohki, T.; Shibata, N.: Mizuno, N.; Wakitani, Y.; Tsurukame, J.; Matsumoto, K.; Kawamoto, I.; Takeo, M.; Higuchi, Y. X-ray Crystallographic Analysis of 6-Aminohexanoate-Dimer Hydrolase. J. Biol. Chem. 2005, 280, 39644-39652. Negoro, S.; Ohki, T.; Shibata, N.; Sasa, K.; Hayashi, H.; Nakano, H.; Yasuhira, K.; Kato, D.; Takeo, M.; Higuchi, Y. Nylon-oligomer Degrading Enzyme/Substrate Complex: Catalytic Mechanism of 6-Aminohexanoate-Dimer Hydrolase. J. Mol. Biol. 2007, 370, 142-156. 
Kawashima, Y.; Ohki, T.; Shibata, N.; Higuchi, Y.; Wakitani, Y.; Matsuura, Y.; Nakata, Y.; Takeo, M.; Kato, D.; Negoro, S. Molecular Design of a Nylon-6 ByproductDegrading Enzyme from a Carboxylesterase with a $\beta$-Lactamase Fold. FEBS J. 2009, 276, 2547-2556.

Ohki, T.; Shibata, N.; Higuchi, Y.; Kawashima, Y.; Takeo, M.; Kato, D.; Negoro, S. Two Alternative Modes for Optimizing Nylon-6 Byproduct Hydrolytic Activity from a Carboxylesterase with a $\beta$-Lactamase Fold: X-ray Crystallographic Analysis of Directly Evolved 6-Aminohexanoate-Dimer Hydrolase. Protein Sci. 2009, 18, 1662-1673.

Baba, T.; Kamiya, K.; Matsui, T.; Shibata, N.; Higuchi, Y.; Kobayashi, T.;

Negoro, S.; Shigeta, Y. Molecular Dynamics Studies on the Mutational Structures of a Nylon-6 Byproduct-Degrading Enzyme. Chem. Phys. Lett. 2011, 507, 157-161.

(21) Case, D. A.; Darden, T. A.; Cheatham, T. E.; Simmerling, C. L.; Wang, J.; Duke, R. E.; Luo, R.; Merz, K. M.; Wang, B.; Pearlman, D. A.; et al. 2004, AMBER 8, University of California, San Francisco.

Hohenberg, P; Kohn, W. Inhomogeneous Electron Gas. Phys. Rev. 1964, 136, B864-B871.

Kohn, W.; Sham, L. J. Self-Consistent Equations Including Exchange and Correlation Effects, Phys. Rev. 1965, 140, A1133-A1138.

Hamprecht, F. A.; Cohen, A. J.; Tozer, D. J.; Handy, N. C. Development and Assessment of New Exchange-Correlation Functionals. J. Chem. Phys. 1998, 109, 62646271.

$$
\text { Car, R.; Parrinello, M. Unified Approach for Molecular Dynamics and Density- }
$$
Functional Theory, Phys. Rev. Lett. 1985, 55, 2471-2474. CPMD, http://www.cpmd.org/, Copyright IBM Corp. 1990-2008, Copyright MPI für Festkörperforschung Stuttgart 1997-2001. 
Electrostatic Potential Derived Charges from Quantum Mechanics/Molecular Mechanics Simulations. J. Phys. Chem. B 2002, 106, 7300-7307. U.S.A. 2002, 99, 12562-12566. Iannuzzi, M.; Laio, A.; Parrinello, M. Efficient Exploration of Reactive Potential Energy Surfaces Using Car-Parrinello Molecular Dynamics, Phys. Rev. Lett. 2003, 90 , 238302-1-238302-4.

Boero, M.; Ikeda, T.; Ito, E.; Terakura, K. Hsc70 ATPase: An Insight into Water Dissociation and Joint Catalytic Role of $\mathrm{K}^{+}$and $\mathrm{Mg}^{2+}$ Metal Cations in the Hydrolysis Reaction. J. Am. Chem. Soc. 2006, 128, 16798-16807.

Dal Peraro, M.; Ruggerone, P.; Raugei, S.; Gervasio, F. L.; Carloni, P. Investigating Biological Systems Using First Principles Car-Parrinello Molecular Dynamics Simulations. Curr. Opin. Struct. Biol. 2007, 17, 149-156. Kamiya, K.; Boero, M.; Tateno, M.; Shiraishi, K.; Oshiyama, A. Possible Mechanism of Proton Transfer through Peptide Groups in the H-Pathway of the Bovine Cytochrome $c$ Oxidase. J. Am. Chem. Soc. 2007, 129, 9663-9673. Pietrucci, F.; Marinelli, F.; Carloni, P.; Laio, A. Substrate Binding Mechanism of HIV-1 Protease from Explicit-Solvent Atomistic Simulations. J. Am. Chem. Soc. 2009, 131, 11811-11818. Petersen, L.; Ardèvol, A.; Rovira, C.; Reilly, P. J. Molecular Mechanism of the Glycosylation Step Catalyzed by Golgi $\alpha$-Mannosidase II: A QM/MM Metadynamics Investigation. J. Am. Chem. Soc. 2010, 132, 8291-8300. 
McDonough, M. A.; Anderson, J. W.; Silvaggi, N. R.; Pratt, R. F.; Knox, J. R.;

Kelly, J. A. Structures of Two Kinetic Intermediates Reveal Species Specificity of Penicillin-Binding Proteins. J. Mol. Biol. 2002, 322, 111-122.

Kelly, J. A.; Kuzin, A. P. The Refined Crystallographic Structure of a DDPeptidase Penicillin-Target Enzyme at 1.6 Å Resolution. J. Mol. Biol. 1995, 254, 223-236.

Gladioli: A Novel Esterase with a $\beta$-Lactamase Fold Reveals Steric Factors to Discriminate between Esterolytic and $\beta$-Lactam Cleaving Activity. Protein Sci. 2002, 11, 467-478.

Beadle, B. M.; Trehan, I.; Focia, P. J.; Shoichet, B. K. Structural Milestones in the Reaction Pathway of an Amide Hydrolase: Substrate, Acyl, and Product Complexes of Cephalothin with AmpC $\beta$-Lactamase. Structure 2002, 10, 413-424.

(39) Powers, R. A.; Shoichet, B. K. Structure-Based Approach for Binding Site Identification on AmpC $\beta$-Lactamase. J. Med. Chem. 2002, 45, 3222-3234.

Schutz, C. N.; Warshel, A. The Low Barrier Hydrogen Bond (LBHB) Proposal Revisited: The Case of the Asp $\cdots$ His Pair in Serine Proteases, Proteins 2004, 55, 711-723.

(41) Bürgi, H. B.; Dunitz, J. D.; Shefter, E. Chemical Reaction Paths. IV. Aspects of O $\cdots \mathrm{C}=\mathrm{O}$ Interactions in Crystals. Acta. Cryst. 1974, B30, 1517-1527.

Hermann, J. C.; Ridder, L.; Mulholland, A. J.; Höltje, H.-D. Identification of Glu166 as the General Base in the Acylation Reaction of Class A $\beta$-Lactamases through QM/MM Modeling. J. Am. Chem. Soc. 2003, 125, 9590-9591.

Ishida, T.; Kato, S. Theoretical Perspectives on the Reaction Mechanism of Serine Proteases: The Reaction Free Energy Profiles of the Acylation Process. J. Am. Chem. Soc. 2003, 125, 12035-12048. 
Hermann, J. C.; Hensen, C.; Ridder, L.; Mulholland, A. J.; Höltje, H.-D.

Mechanisms of Antibiotic Resistance: QM/MM Modeling of the Acylation Reaction of a Class A $\beta$-Lactamase with Benzylpenicillin. J. Am. Chem. Soc. 2005, 127, 4454-4465.

Shi, Q.; Meroueh, S. O.; Fisher, J. F.; Mobashery, S. Investigation of the Mechanism of the Cell Wall DD-Carboxypeptidase Reaction of Penicillin-Binding Protein 5 of Escherichia coli by Quantum Mechanics/Molecular Mechanics Calculations. J. Am. Chem. Soc. 2008, 130, 9293-9303.

Shi, Q.; Meroueh, S. O.; Fisher, J. F.; Mobashery, S. A Computational Evaluation of the Mechanism of Penicillin-Binding Protein-Catalyzed Cross-Linking of the Bacterial Cell Wall. J. Am. Chem. Soc. 2011, 133, 5274-5283.

Sharma, S.; Bandyopadhyay, P. Investigation of the Acylation Mechanism of Class C Beta-Lactamase: pKa Calculation, Molecular Dynamics Simulation and Quantum Mechanical Calculation. J. Mol. Model 2012, 18, 481-492. Silvaggi, N.R.; Josephine, H. R.; Kuzin, A. P.; Nagarajan, R.; Pratt, R. F.; Kelly, J. A. Crystal Structures of Complexes between the R61 DD-Peptidase and PeptidoglycanMimetic $\beta$-Lactams: A Non-Covalent Complex with a "Perfect Penicillin". J. Mol. Biol. 2005, 345, 521-533. Deslongchamps, P. Stereoelectronic Control in the Cleavage of Tetrahedral Intermediates in the Hydrolysis of Esters and Amides. Tetrahedron 1975, 31, 2463-2490.

Stereoelectronic, Structural, and Kinetic Considerations as Guidelines To Deduce Reaction Paths. Acc. Chem. Res. 1989, 22, 322-327. Radisky, E. S.; Lee, J. M.; Lu, C.-J. K.; Koshland, D. E. Insights into the Serine Protease Mechanism from Atomic Resolution Structures of Trypsin Reaction Intermediates. Proc. Natl. Acad. Sci. U.S.A. 2006, 103, 6835-6840. 

Warchel, A.; Sharma, P. K.; Kato, M.; Xiang, Y.; Liu, H.; Olsson, M. H. M. Electrostatic Basis for Enzyme Catalysis. Chem. Rev. 2006, 106, 3210-3235. Compensation Mechanism for Charge-Separated Protonation States in AspartateHistidine Amino Acid Residue Pairs. J. Phys. Chem. B 2010, 114, 6567-6578. Tripathi, R.; Nair, N. N. Thermodynamic and Kinetic Stabilities of Active Site Protonation States of Class C $\beta$-Lactamase. J. Phys. Chem. B 2012, 116, 4741-4753. 